\title{
Percutaneous Nephrolithotomy: A Rare Vascular Complication
}

Othmane El Houadfi ${ }^{*}$, Amine Saouli, Omar Jendouzi, Mohamed Alami, Ahmed Ameur

Urology Department of the Mohammed V Military Instruction Hospital, Faculty of Medicine and Pharmacy, Mohamed V University, Rabat, Morocco

\begin{tabular}{|c|c|}
\hline DOI: $\underline{10.36347 / \text { sasjm.2021.v07i05.008 }}$ & Received: 12.04 .2021 | Accepted: 19.05.2021 | Published: 27.05.2021 \\
\hline *Corresponding author: Dr. Othmane 1 & \\
\hline Abstract & Case Report \\
\hline $\begin{array}{l}\text { We report the case of a } 64 \text {-year-ol } \\
\text { left kidney complicated by an arteri } \\
\text { by embolization of the damaged } v \\
\text { will insist on the precise knowledge } \\
\text { of PCNL. } \\
\text { Keywords: arteriovenous fistula, } p\end{array}$ & $\begin{array}{l}\text { ented with a pseudoaneurysm of the inferior polar artery of the } \\
\text { ondary to percutaneous nephrolithotomy (PCNL). The treatment } \\
\text { ad been carried out successfully. Through this observation, we } \\
\text { I vascular anatomy which is essential for the proper performance } \\
\text { Iney, embolization. }\end{array}$ \\
\hline $\begin{array}{l}\text { Copyright } \odot 2021 \text { The Author(s): This is a } \\
\text { License (CC BY-NC 4.0) which permits unr } \\
\text { author and source are credited. }\end{array}$ & $\begin{array}{l}\text { stributed under the terms of the Creative Commons Attribution 4.0 International } \\
\text { n, and reproduction in any medium for non-commercial use provided the original }\end{array}$ \\
\hline
\end{tabular}

\section{INTRODUCTION}

NLPC is a safe and reliable technique in the treatment of kidney stones [1]. Recently, the efficacy and reliability of this procedure is being improved due to advances in technology and increased experience in this field. However, it is not free of certain complications. Hemorrhage represented by pseudoaneurysm and arteriovenous fistula is one of the most dangerous complications that can be seen after NLPC. Selective and hyperselective embolization has revolutionized the management of post-NLPC vascular complications refractory to conservative treatment $[2$, 3].

\section{OBSERVATION}

Our patient is a 64-year-old male, hypertensive on treatment, previously operated for a left renal stone in 2010 by lumbotomy.

Admitted to our training for the management of a recurrence of the left pyelic stone. Biologically, renal function was normal with a negative urine cytobacteriological examination.

Our patient underwent a left percutaneous nephro-lithotomy. Subsequently, persistent hematuria developed, resulting in recurrent bladder clotting.

Clinically, our patient had hemodynamic instability; $\mathrm{BP}=09.07, \mathrm{HR}=110 \mathrm{bpm}$, with mucocutaneous pallor. As well as a deglobulation that required iterative transfusions.
The patient underwent an emergency angioscan (Figure 1 A, B), which showed a perirenal hematoma with a false aneurysm of the inferior polar artery complicated by an arteriovenous fistula.

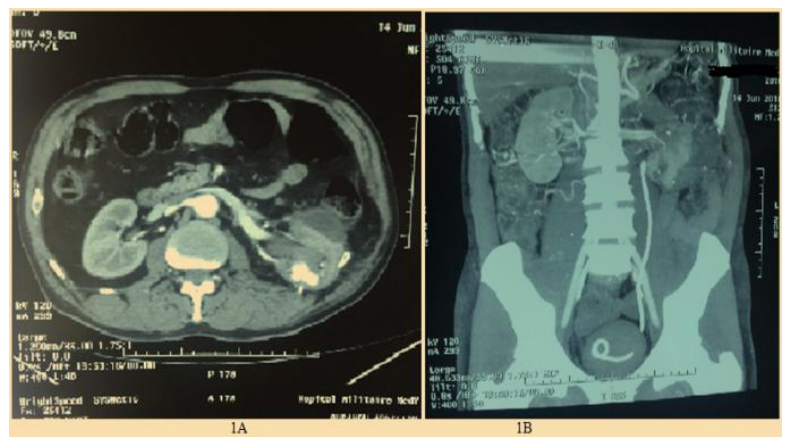

Fig-1A, 1B: Axial A and frontal B scans after injection of contrast medium showing a false aneurysm of the inferior polar artery complicated by an arteriovenous fistula with a left perirenal hematoma, moreover, we note the presence of a few residual calculi the largest at $30 \mathrm{~mm} A$, with a good positioning of the double $J$ probe on the left $B$.

An embolization was done in emergency by placing coils. The evolution was marked by the cessation of hematuria in the immediate following and a control by a renal scintigraphy with DMSA (dimercaptosuccinic acid) which showed a functional value at $26 \%$ at the level of the left kidney compared to $74 \%$ at the level of the right kidney and a uroscanner two months post NLPC confirmed the disappearance of vascular lesions figure 2 . 


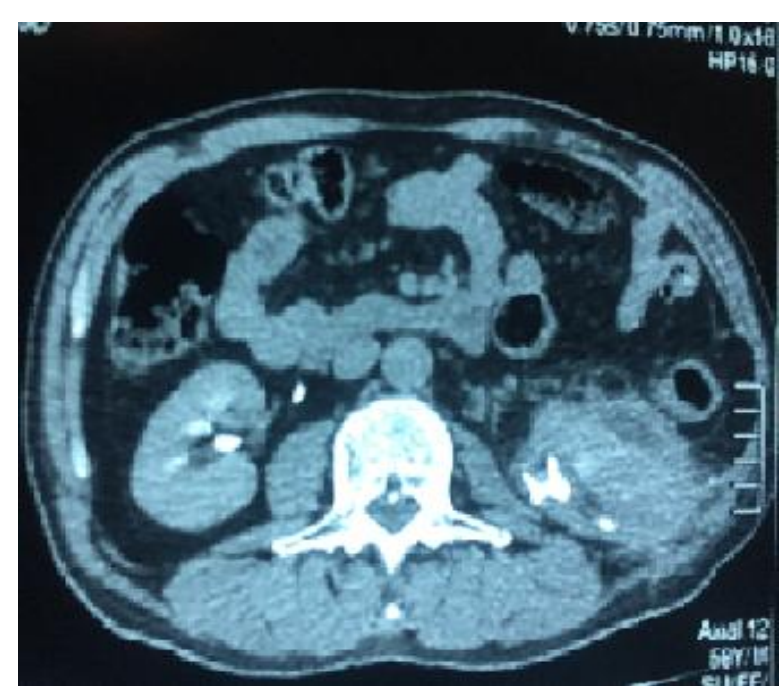

Fig-2: Axial CT slice with contrast injection in late time showing the favorable evolution after embolization two months post-NLPC with spontaneous resorption of the perirenal hematoma and drying of the vascular lesions.

\section{DISCUSSION}

The first percutaneous nephrolithotomy (NLPC) was described in 1955 by Goodwin and was developed by Fernström and Johansson in 1977.

In the early 1980s, NLPC was the gold standard treatment technique for proximal renal and ureteral calculi [4] alongside ureterorenoscopy (URS); both were less aggressive than open surgery until the spread of extracorporeal lithotripsy (ECL) in 1982 [5].

Complications of NLPC were often described in the 1980s when this technique was innovative before the diffusion of ECL. [4, 6] They were evaluated at $26 \%$ on average, including minor complications (nonfebrile urinary tract infection, displacement, blockage on removal or obstruction of the nephrostomy tube) and major complications which may be haemorrhagic, urinary, related to lesions of neighbouring organs, infectious or metabolic [7]. They remain dependent on a learning curve and decrease from 15 to $1.5 \%$ after about twenty procedures $[8,9]$.

Seitz et al.[10] studied the prevalence of NLPC complications through the different articles from 2001 to 2011 , according to the Clavien classification, $88 \%$ of patients in Clavien $1,7 \%$ in Clavien $2,4.1 \%$ in Clavien 3 and Clavien 4 to $0.6 \%$.

Vascular complications are represented by arteriovenous fistula, arteriocal fistula, aneurysm, pseudoaneurysm or perinephric hematoma [11].

The risk of bleeding after NLPC has been estimated to be $0.8 \%$ to $17 \%$ depending on how bleeding events are defined the overall transfusion rate was estimated at $7.9 \%$ in a prospective series of 301 cases [12].
The mean time to onset of hematuria after NLPC was 5.8 days (3-11 days), and the mean hospitalization during the second admission was 5.4 days (4-16 days) [13]. A prospective study in multivariate analysis identified the predictive factors of post-NLPC hemorrhagic risk as diabetes, previous NLPC, puncture location either by ultrasound or image intensifier, the method of dilatation by balloon or Amplatz or Alken, the number and diameter of the trajectory, intraoperative complications such as stem tear, pyloric wound or sheath exit and operative time.

Age, hypertension, presence of urinary tract infection, renal failure, degree of cavity dilatation, and stone surface area did not significantly influence bleeding risk [14]. Therapeutically, two treatment modalities are proposed. Interventional radiology allows selective embolization of the fistula [15-19]. BOOKSTEIN and GOLDSTEIN, in 1973, were the first to develop this procedure for the treatment of AVF after renal biopsy. Since then, several embolizing substances have been used: gelatin, subcutaneous tissue and muscle, formalized polyvinyl alcohol, cyanoacrylate, lead or steel coils, and balloons used in neuroradiology.

Currently, with the help of new spider-shaped vascular occlusion devices, this method can even be proposed in the treatment of large fistulas, with a low risk of pulmonary embolism [17, 20, 21, 22]. Complications of embolization are rare: one case of post-embolization arterio-caliceal fistula has been described [19]. The risk of tubular necrosis is exceptional [23].

According to Sitki Un and colleagues showed that in a series of 1405 patients who underwent NLPC, 147 had postoperative hematuria requiring transfusion, 133 were treated conservatively, while 14 patients became hemodynamically unstable and underwent angiography with embolization. The success rate of this technique was about $100 \%$ [24]. Surgical treatment allows either an excisional procedure, performing total or partial nephrectomy or ligation of the arterial branches supplying the fistula $[15,23,25]$, or an extracorporeal or in situ reconstruction procedure $[15,17]$ using vascular microsurgery techniques [26], allowing preservation of renal function.

\section{CONCLUSION}

Arteriovenous fistula is a serious complication that must be evoked in post cutaneous nephrolithotomy if deglobulation and hemodynamic disorder the radiointerventional is the least invasive solution to manage this situation. The miniaturization of endoscopic equipment and the laser will reduce the frequency of this complication. 


\section{REFERENCES}

1. Ritter, M., Krombach, P., \& Michel, M. S. (2011). Percutaneous stone removal. European urology supplements, 10(5), 433-439.

2. Martin, X., Murat, F. J., Feitosa, L. C., Rouviere, O., Lyonnet, D., Gelet, A., \& Dubernard, J. M. (2000). Severe bleeding after nephrolithotomy: Results of hyperselective embolization. European urology, 37(2), 136-139.

3. Mavili, E., Dönmez, H., Özcan, N., Sipahioglu, M., \& Demirtas, A. (2009). Transarterial embolization for renal arterial bleeding. Diagnostic and Interventional Radiology, 15(2), 143.

4. Segura, J. W., Patterson, D. E., Leroy, A. J., Williams, H. J., Barrett, D. M., Benson, R. C., ... \& Bender, C. E. (1985). Percutaneous removal of kidney stones: review of 1,000 cases. The Journal of urology, 134(6), 1077-1081.

5. Chaussy, C., \& Schmiedt, E. (1983). Shock wave treatment for stones in the upper urinary tract. The Urologic Clinics of North America, 10(4), 743-750.

6. Lingeman, J. E., Coury, T. A., Newman, D. M., Kahnoski, R. J., Mertz, J. H., Mosbaugh, P. G., ... \& Woods, J. R. (1987). Comparison of results and morbidity of percutaneous nephrostolithotomy and extracorporeal shock wave lithotripsy. The Journal of urology, 138(3), 485-490.

7. Radecka, E., \& Magnusson, A. (2004). Complications associated with percutaneous nephrostomies. A retrospective study. Acta radiologica, 45(2), 184-188.

8. Lang, E. K. (1987). Percutaneous nephrostolithotomy and lithotripsy: a multiinstitutional survey of complications. Radiology, 162(1), 25-30.

9. Le Duc, A. (1991). Les complications immédiates de la chirurgie percutanée du rein. Progrès en urologie, 1(1), 31-35.

10. Seitz, C., Desai, M., Häcker, A., Hakenberg, O. W., Liatsikos, E., Nagele, U., \& Tolley, D. (2012). Incidence, prevention, and management of complications following percutaneous nephrolitholapaxy. European urology, 61(1), 146158.

11. Maleux, G., Messiaen, T., Stockx, L., Vanrenterghem, Y., \& Wilms, G. (2003). Transcatheter Embolization of Biopsy- Related Vascular Injuries in Renal Allografts: Long- term technical, clinical and biochemical results. Acta Radiologica, 44(1), 13-17.

12. Nouralizadeh, A., Ziaee, S. A. M., Hosseini Sharifi, S. H., Basiri, A., Tabibi, A., Sharifiaghdas, F., ... \& Soltani, M. H. (2014). Delayed postpercutaneous nephrolithotomy hemorrhage: prevalence, predictive factors and management. Scandinavian journal of urology, 48(1), 110-115.

13. Dore, B. (2006, June). Complications of percutaneous nephrolithotomy: risk factors and management. In Annales d'urologie (Vol. 40, No. 3, pp. 149-160).

14. Armstrong A.L., Birch, B.R., Jenkins, J.D. (1994). Renal arteriovenous fistula following blunt trauma. Br. J. Urol, 73, 321-322.

15. Chivate, J.G., Blewitt, R.W. (1993). Congenital renal arteriovenous fistula. Br. J. Urol., 71, 358359.

16. Heyns, C.F. (1992). Van vollenhoven P. Selective surgical management of renal stab wounds. Br. J. Urol, 69, 351-357.

17. Heyns, C.F., Van vollenhoven, P. (1992). Increasing role of angiography and segmental artery embolization in the management of renal stab wounds. J. Urol. 147, 1231-1234.

18. Huppert, P.E., Duda, S.H., Erley C.M., Roth, M., Lauchart, W., Dietz, K., Claussen C.D. (1993). Embolization of renal vascular lesions : clinical experience with microcoils and tracker catheters. Cardiovasc. Intervent. Radiol, 16, 361-367.

19. Kearse, W. S. Jr., Joseph, A.E., Sabanegh, E.S. Jr. (1994). Transcatheter embolization of large idiopathic renal arteriovenous fistula. J. Urol. 151, 967-969.

20. Khan, A.B., Reid, A.W. (1994). Management of renal stab wounds by arteriographic embolization. Scand. J. Urol. Nephrol, 28, 109-110.

21. Libertino, J.A. (1992). Renovascular, Surgery. In: Walsh P.C., Retik A.B., Stamey T.A., Vaughan E.D. Jr. (Eds.): Campbell's Urology, 6th Ed., Philadelphia, W.B. Saunders Co, 2521-2551.

22. Marchal, escalona, C., Chicharro, Molero, J.A., Delrosal samaniego, J.M., Ruiz dominguez, J.L., Fuentes lupianez, C., Burgos, Rodriguez, R. (1993). Fistula arteriovenosa como complicacion de la nefrostomia percutanea. Arch. Esp. Urol., 46, 807-809.

23. Matsell, D.G., Jones, D.P., Boulden, T.F., Burton, E.M., Baum, S.L., Tonkin, I.L. (1992). Arteriovenous fistula after biopsy of renal transplant kidney : diagnosis and treatment. Pediatr. Nephrol, 6, 562-564.

24. Robinson, D.L., Teitelbaum, G.P., Pentecost, M.J., Weaver, F.A., Finck, E.J. Transcatheter embolization of an aortocaval fistula caused by residual renal artery stump from previous nephrectomy: A case report. J. Vasc. Surg., 17, 794-797.

25. Vanhoenacker, P., Crolla, D., Debakker, G., Verbanck, J. (1993). Transition of renal arteriovenous fistula to arteriocalyceal fistula during embolization. J. Belg. Radiol, 76, 316-317.

26. Sitki, U.N., Volkan, C., Cengiz, K., Hakan, T., Osman, K., Omur, B., \& Yuksel, Y. (2015). Risk factors for hemorrhage requiring embolization after percutaneous nephrolithotomy, Can Urol Assoc J, Sep-Oct; 9(9-10): E594-E598. 